\title{
O campo da saúde do trabalhador sob o crivo do mal-estar como fundamento ético
}

\section{The worker's health field under the rift of malaise as the ethical ground}

\section{El campo de la salud del trabajador bajo la cueva del malestar como fundamento ético}

\author{
Elaine Cristina Schmitt Ragnini* \\ Universidade Federal do Paraná - UFPR, Paraná, Brasil \\ Vinicius Anciães Darriba** \\ Universidade do Estado do Rio de Janeiro - UERJ, Rio de Janeiro, Brasil
}

\begin{abstract}
RESUMO
Este artigo analisa, desde a perspectiva da clínica psicanalítica, a qual se apoia na noção de mal-estar, alguns elementos das práticas de saúde desenvolvidas no campo que se volta para a relação entre saúde e trabalho, acompanhando a constituição de saberes e práticas que buscam circunscrever tal relação, verifica-se a exclusão do sujeito em sua acepção associada ao inconsciente freudiano. Finalmente, indica-se que o campo da Saúde do Trabalhador, em sua perspectiva contra-hegemônica, crítica ao modo de produção no capitalismo, acaba por reiterar uma ordem de coisas agenciada segundo a lógica do capital quando, na busca de um nexo causal entre doença e trabalho, ratifica o estatuto epidêmico da depressão nos termos da psiquiatria biológica.
\end{abstract}

Palavras-chave: saúde, trabalhador, mal-estar, sujeito, inconsciente.

\section{ABSTRACT}

This article analyzes, from the perspective of psychoanalytic clinic, which relies on malaise notion, some elements of health practices developed in the field that turns to the relationship between health and work. Following the constitution of knowledge and practices that seek to circumscribe this relationship, it notes the exclusion of the subject in it meaning associated with the Freudian unconscious. Finally, it is stated that the field of Worker's Health, in its counter-hegemonic perspective, critical of the mode of production in capitalism, turns out to reiterate an order of things associated with the logic of capital when, in the search for a causal link between illness and work, it confirms the epidemic status of depression in terms of biological psychiatry.

Keywords: worker, health, malaise, subject, unconscious.

\section{RESUMEN}

El artículo analiza, desde la perspectiva de la clínica psicoanalítica, que se basa en la noción de malestar, algunos elementos de las prácticas de salud 
desarrolladas en el campo que convierte a la relación entre la salud y el trabajo. Siguiendo la constitución de conocimientos y prácticas que tratan de circunscribir esta relación, comprueba la exclusión del sujeto en su dirección asociada con el inconsciente freudiano. Por último, se indica que el campo de la Salud del Trabajador, en su perspectiva contra hegemónica, crítica del modo de producción en el capitalismo, resulta reiterar un orden de cosas promocionado de acuerdo a la lógica del capital, cuando, en la búsqueda de una relación causal entre la enfermedad y el trabajo, confirma el estado epidemia de depresión en términos de la psiquiatría biológica.

Palabras clave: salud, trabajador, malestar, sujeto, inconsciente.

\section{I ntrodução}

A práxis inaugurada por Freud coloca em cena o inconsciente. Ao não priorizar a mera extinção dos sintomas, ele perfaz a via de acesso ao inconsciente e de encontro com a problemática do desejo. No desenvolvimento de seu trabalho clínico, que se distinguia cada vez mais da clínica médica e psiquiátrica da época, Freud investe na compreensão da estrutura e da dinâmica do psiquismo e dos meios de acesso ao inconsciente, certificando-se de que o mesmo encontra suas bases nas experiências de satisfação, ou seja, na sexualidade, e na relação ao outro. Essa descoberta institui que aquilo que se toma na ordem de uma psicologia individual e de uma psicologia coletiva são indissociáveis (Freud, 1921/1998d).

O investimento sexual na relação com outros humanos e com a cultura confere ao sujeito satisfação, mas também um limite à mesma. No intuito de abordar tal impasse, Freud (1930[1929]/1998f) articula a noção de mal-estar. Essa divergência entre a exigência de satisfação pulsional e os requisitos da cultura já é apontada e trabalhada por Freud desde o início da teorização de sua clínica, quando desenvolve a compreensão acerca da etiologia das neuroses e do desenvolvimento da sexualidade (Freud, 1898/1998a; 1905/1998b; 1908/1998c), estendendo-se aos trabalhos das décadas de 1920 e 1930, quando aborda mais delimitadamente a relação do sofrimento psíquico com a cultura (Freud, 1927/1998e; 1930[1929]/1998f; 1933/1998/g).

Nestes termos, uma clínica que se apoia na noção de mal-estar visa abordar o sintoma como algo singular a cada sujeito, mas que, em alguma medida, encontra-se intimamente relacionado ao discurso vigente na época; portanto, à posição desde a qual o sujeito responde às exigências do Outro. Essa clínica também pressupõe uma ética, a qual se funda justamente no que o mal-estar delimita: a inscrição de uma impossibilidade como ponto de partida para o trabalho clínico, já que associada a uma falha estrutural incidindo sobre o ideal de complementaridade entre a plena realização da satisfação pulsional e o requisito civilizatório. 
Situados desde esta perspectiva, propomo-nos analisar aqui alguns elementos das práticas de saúde desenvolvidas no campo teórico e prático que se volta para (buscando circunscrever como tal) a relação entre saúde e trabalho. Esse campo, que se desenvolveu a partir da medicina e incorporou outras áreas do conhecimento, pretende-se afeito à saúde do trabalhador na medida em que visa curar seu adoecimento, seja pela via do corpo ou das condições externas que fazem adoecer. No entanto, ele também encontra-se ligado às exigências do capital, na medida em que visa restabelecer a condição do trabalhador de estar apto e produtivo para o trabalho, o que implica que em seu âmbito tenham igualmente emergido doutrinas com pretensões emancipatórias, críticas a esta redução do trabalhador a força produtiva.

\section{A constituição de saberes e práticas na relação entre saúde e trabalho}

Nas últimas quatro décadas, o registro de doenças relacionadas ao trabalho tem aumentado significativamente no Brasil, com um índice também cada vez maior de adoecimentos psíquicos que se dizem relacionados ao trabalho. Desde 1990, dentre os diagnósticos mais comuns encontram-se a depressão e os quadros de ansiedade (Cruz, 2010). Já são igualmente conhecidas algumas doenças produzidas no e pelo trabalho, como o burn-out (esgotamento físico e psíquico no trabalho) e a síndrome de karoshi (morte súbita provocada por excesso de trabalho), e fenômenos clínicos cuja responsabilidade é atribuída pelos especialistas (Dejours e Bègue, 2010; Netto, 2013) ao contexto do trabalho, como o suicídio. A organização de uma área da saúde para lidar especialmente com aquilo que o trabalho produz significa um avanço para as relações de trabalho, mas ao mesmo tempo implica alguma reflexão, já que o adoecimento passa a ser entendido como causado por um mal funcionamento do corpo biológico ou pela forma como o trabalho está organizado. Interrogamos se essas duas visadas sobre o adoecimento psíquico relacionado ao trabalho excluiriam o sujeito, em sua acepção associada ao inconsciente freudiano, na medida em que sobsomem a problemática clínica em jogo às questões do corpo e/ou das condições de trabalho, objetivando-a e apartando-a do domínio da linguagem enquanto que constitutivo.

É antigo o esforço de filósofos e médicos em estabelecer alguma associação entre as doenças e as atividades de trabalho desenvolvidas pela população. Na Idade Média, tem-se como marco dos estudos dessa relação, o livro do médico italiano Bernardino Ramazzini, denominado As doenças dos trabalhadores (1700/2000), que abordou, pela primeira vez, um estudo ampliado sobre as doenças de mais de 
cinquenta profissões, demarcando uma nova leitura sobre as doenças relacionadas ao trabalho. Passou a estar implicado o olhar do médico sobre a doença para além do corpo, ou seja, também para as condições de vida e laborais dos trabalhadores, e o trabalho da medicina voltado para a população economicamente desfavorecida.

Com o advento da Revolução Industrial e o desenvolvimento da ciência, organizou-se, ao longo do tempo, um campo específico de saberes e práticas para abordar a relação entre a doença e o trabalho, podendo-se citar, dentro das especialidades médicas, a Medicina do Trabalho, a Saúde Ocupacional e a Saúde do Trabalhador. Também outras áreas da saúde como a psicologia, a enfermagem e a fisioterapia passaram a atuar sobre essa problemática. As práticas consolidadas em cada área ou especialidade trouxeram em seu bojo não só uma operação para a extinção do que causa o impedimento para o trabalho, mas também um ideal de cura, que sinaliza, para cada especialidade da saúde envolvida, se a causa e a solução do problema se restringem ao corpo ou se podem ampliar-se para as relações deste corpo e desse indivíduo com a realidade, ou seja, para as condições de trabalho que lhe são dadas e o modo como os próprios indivíduos se organizam coletivamente para o trabalho.

O período denominado Revolução Industrial é conhecido por seus efeitos na vida e na saúde da população, determinante de novas formas de agir, produzir e se relacionar, consolidando uma estrutura societal a partir de classes distintas: o proletariado e a burguesia. Demarcado pelas exigências de produção e de submissão do homem às condições precárias dos contextos das fábricas no século XVIII, o trabalho humano passa a ser realizado nelas sob a égide de um controle rigoroso, muitas e intensas horas de trabalho, atividades repetitivas, com a utilização de mulheres e crianças nas atividades de produção e sob condições de intenso frio ou calor. Não sem demora, estudos e avaliações médicas sobre as condições de saúde desses trabalhadores passam a ser realizados, sendo utilizados como recurso para o desenvolvimento de políticas e ações de proteção a esses trabalhadores.

Mendes e Dias (1991) citam o caso do proprietário de uma fábrica na Inglaterra que, em 1830, chama seu médico particular para ajudá-lo a resolver os problemas de saúde dos seus empregados. As péssimas condições de trabalho e de vida da população da época ameaçavam a ordem vigente e comprometiam a capacidade de produção das fábricas. Nesse cenário, algumas leis foram criadas para proteger a saúde da população e dos trabalhadores e normatizar as condições sanitárias das fábricas e das cidades. A relação entre trabalho e saúde também passou a incluir a análise da morbidade e da mortalidade dos trabalhadores.

Ao longo do século $X X$, as patologias do trabalho, inicialmente compreendidas no âmbito da medicina social, passaram a ser tratadas 
no âmbito da higiene, acompanhando o movimento higienista, e localizando numa causa específica o desenvolvimento da doença. Os agentes etiológicos das doenças dos trabalhadores passaram a ser os agentes físicos (ruído, calor, frio, radiação), biológicos e químicos (mercúrio, chumbo, benzeno) presentes no contexto do trabalho (Mendes e Waissmann, 2007). Nesse cenário, a Medicina do Trabalho ganhou corpo e destaque, aliando-se ao capital com o objetivo de medicalizar as doenças relacionadas ao trabalho e minimizar as possíveis ligações entre o trabalho e o adoecimento dos trabalhadores, fortalecendo a visada de uma medicina ambientalista e com foco nos agentes promotores de agravos e doenças nos trabalhadores (Waissmann e Castro, 1996).

Também no século XX, em função das mudanças ocorridas no sistema produtivo e da criação e desenvolvimento das leis de proteção aos trabalhadores, estabeleceram-se nas fábricas e, por extensão, em outros locais de trabalho, sistemas de gestão da saúde e da segurança dos trabalhadores. Ao mesmo tempo em que se desenvolveu uma consciência crítica em relação aos efeitos do modo de trabalho capitalista sobre a vida e a saúde dos trabalhadores, prosperou dentro do sistema de capital um subsistema que propunha amenizar e regular esses efeitos sobre a saúde, estabelecido nos serviços de medicina e segurança do trabalho organizados nas fábricas.

Com o desenvolvimento do capitalismo e da ciência administrativa, uma série de transformações ocorreu na forma de vida e de relação da população em geral. A demanda por produtividade e eficiência nas fábricas impôs novos ritmos de trabalho e novas formas de se relacionar com o trabalho, o que vem acompanhado a formas do trabalhador responder a isso. Assim, é no limite entre a máxima produtividade possível e o risco de extinção da força produtiva apta a essa produção que se equilibram as demandas e as exigências do capital. Mesmo contando com um exército industrial de reserva, sabese que há um limite para as exigências de produtividade, bem como há a resistência por parte dos trabalhadores a formas desumanas e degradantes de produção.

As dificuldades provocadas pelo aumento da produção, especialmente pós-Segunda Guerra Mundial, fizeram aumentar o número de acidentes e adoecimentos relacionados ao trabalho. Nesse momento, a Medicina do Trabalho constatou uma aparente impossibilidade de atuar sobre os problemas de saúde advindos das necessidades e dos processos de produção. Assim, pela lógica racionalista e científica imperante no processo produtivo e de gestão, decidiu-se por ampliar sua atuação, inicialmente localizada sobre o trabalhador e seu corpo. Essa ampliação supunha uma atuação dos médicos também sobre 0 ambiente de trabalho, ou seja, a administração passou a utilizar-se de outras disciplinas, outros instrumentos e outros profissionais para operar também sobre o ambiente e buscar a redução dos acidentes e 
doenças relacionados ao trabalho (Mendes e Dias, 1991). Essa mudança de foco de atuação culminou na construção do campo denominado Saúde Ocupacional, que ampliou a atuação da medicina do trabalho e, segundo Rocha (2010), passou "a avaliar não apenas o indivíduo, mas o grupo de trabalhadores expostos e não expostos a agentes patogênicos, visando a agir no nível de prevenção no ambiente de trabalho" (p. 11).

\section{- Campo da Saúde do Trabalhador como Proposta Contra- Hegemônica}

O que vimos até aqui em termos de aparato conceitual para compreender a saúde e a doença e suas relações com o trabalho não possui caráter exclusivo. Atualmente, o campo denominado Saúde do Trabalhador configura uma proposta contra-hegemônica a tal modelo para a compreensão e a intervenção nas ditas patologias do trabalho, considerando seus aspectos sociais, políticos, jurídicos e ideológicos. Ele desenvolveu-se no Brasil no final da década de 1970 e meados da década de 1980, face à complexidade que envolve a compreensão e a atuação sobre a saúde em tempos de técnicas altamente sofisticadas de gestão, de altas exigências de produtividade, de avaliações excessivas, de metas impossíveis de serem alcançadas, de flexibilidade generalizada e de desemprego, temas e relações comumente abordados pelos movimentos sociais críticos na relação com o trabalho.

A Saúde do Trabalhador levou para as instituições públicas, para os sindicatos e para as universidades a possibilidade de pesquisa e de atuação sobre os casos relativos às patologias do trabalho em um viés crítico com relação ao modo de produção capitalista. Para Mendes \& Waissmann (2007), a patologia do trabalho condensa as noções de sofrimento, agravo e dano causado pelo trabalho à saúde de quem trabalha. E a saúde é compreendida como uma condição do indivíduo para realizar aspirações, satisfazer necessidades e enfrentar e mudar o ambiente, um "estado de equilíbrio entre os seres humanos e o meio físico, biológico e social, compatível com plena atividade funcional" (Mendes \& Waissmann, 2007, p. 48).

Sob a denominação Saúde do Trabalhador encontra-se uma diversidade de acepções, ora designando um campo de práticas, ora designando um conjunto de ideias e políticas acerca da saúde daquele que trabalha. Para o Estado brasileiro, trata-se de uma área da Saúde Pública, consolidada nos termos atualmente conhecidos a partir da Constituição Federal (1988) e fortemente influenciada pelos movimentos sindical e social das décadas de 1970 e 1980. Com a instituição do Sistema Único de Saúde (SUS), a Saúde do Trabalhador passou a ser de competência da área da saúde, o que demandou de 
municípios, estados e governo federal a construção de um aparato jurídico para dar sustentação a essa área. A novidade instituída a partir da Constituição Federal de 1988, ensejada especialmente pelos movimentos social e sindical, é a referência ao processo produtivo na sua relação com a produção de saúde/doença da população (Brasil, 2005).

Além de ser um campo de atuação complexo, já que seu objeto (relação saúde-trabalho) implica considerações políticas, econômicas, sociais, de saúde e psíquicas específicas e não necessariamente hegemônicas, ele tem como objetivo o desenvolvimento de "ações no sentido de proporcionar efetivas promoção, proteção da saúde e prevenção dos agravos à saúde relacionados ao trabalho" (Brasil, 2005, p. 11). Assim, aquilo que se destina à Saúde do Trabalhador se relaciona com a possibilidade tanto de promover e preservar a vida e a saúde quanto de reabilitar e restaurar a condição de saúde daquele que trabalha, justamente para que trabalhe e dê conta de sua vida.

O desenvolvimento de políticas e de registros de agravos à Saúde do Trabalhador, a partir do engajamento das ciências sociais no campo da Saúde Coletiva e consequentemente no campo da saúde e trabalho (Lacaz, 1996), implicou a compreensão de que a saúde ou a doença relacionados ao trabalho são um processo social, portanto político. Ou seja, considera-se as determinações e as relações do homem com o social e com o trabalho para compreender o processo saúde-doença. Encontra-se aí a diferença mais notável do campo da Saúde do Trabalhador com o campo da Medicina do Trabalho e da Saúde Ocupacional, já que nestas últimas a relação do homem com o social e o meio ambiente é naturalizada, compreendendo "uma abordagem da relação trabalho-saúde pela ótica das ciências naturais e o biológicoindividual é a forma mais adequada de análise" (Lacaz, 1996, p. 120). No Brasil, a consolidação do campo da Saúde do Trabalhador, aliada ao aumento significativo do registro de casos de adoecimento mental no trabalho, especialmente nos anos de 1990, deram início à construção de uma área específica de pesquisa e intervenção para estes casos. No entanto, trata-se de uma problemática já abordada no início da administração científica e relançada no período pós guerras mundiais. Os primeiros trabalhos desse período foram desenvolvidos pelo psiquiatra francês Louis Le Guillant (1900-1968), que foi integrante do movimento da Psiquiatria Social na França e reconhecido como um psiquiatra de esquerda, já que participava do partido comunista e militava nos sindicatos de classe (Souza e Athayde, 2006). O interesse da Psiquiatria Social era conhecer as condições de vida na sociedade e suas implicações para o desencadeamento ou agravo de problemas mentais.

Nesse sentido, Le Guillant integrou conhecimentos de três campos de saberes distintos - Medicina do Trabalho, psiquiatria social e mundo do trabalho - e buscou formas de conhecer suas relações e intervir 
na realidade, visando "estabelecer verdadeiros nexos causais que ligassem fatos realmente vividos em um determinado ambiente a uma situação concreta de adoecimento", realizando o que chamou de "nova clínica" (Souza e Athayde, 2006, p.12). Dentre seus estudos, pode-se citar a análise do trabalho das telefonistas, das empregadas domésticas e dos condutores de locomotivas. Com isso, Le Guillant pôde estabelecer relações entre as condições de trabalho e os problemas mentais, indicando que se tratava de psicopatologias das profissões (Lhuilier, 2011). Mais recentemente, a Psicopatologia do Trabalho busca avançar no desenvolvimento de pesquisas e novas formas de abordar o adoecimento relacionado ao trabalho. Destacase como contribuição na área também o trabalho de Christophe Dejours (Dejours \& Abdoucheli, 1994), que desenvolveu a Psicodinâmica do Trabalho, apresentada como uma forma de pesquisar, teorizar e intervir sobre as estratégias de defesa dos trabalhadores para lidar com o prazer e o sofrimento no trabalho.

Alguns pesquisadores da área (Selligmann-Silva, 2007, 2011; Mendes e Dias, 1991; Mendes \& Waissmann, 2007) reiteram que as condições e a organização do trabalho são fatores preponderantes para a compreensão e a intervenção no adoecimento psíquico relacionado ao trabalho. Neste sentido, o que "interessa são os processos que, no trabalho, condicionam agravos psicopatológicos de pessoas que trabalham" (Selligmann-Silva, 2007, p. 1142), destacando a autora não haver uma classificação internacional de expressões clínicas das psicopatologias ou distúrbios psíquicos relacionados ao trabalho, apesar de existir um consenso entre os pesquisadores e profissionais da área sobre a importância que 0 trabalho tem assumido no desencadeamento das psicopatologias. Ainda segundo Selligmann-Silva (2007), é na organização do trabalho que os estudos sobre saúde mental e trabalho têm encontrado a fonte "preponderante dos agravos psíquicos relacionados ao trabalho" ( $p$. 1143-1144). Ao longo das últimas duas décadas, no entanto, além da organização do trabalho, estuda-se também o tipo de manifestação do sofrimento e do adoecimento psíquicos relacionados ao trabalho.

Considerando a diversidade de pressupostos, de teorias e de práticas para compreender e intervir no adoecimento psíquico relacionado ao trabalho, pode-se constatar a profusão de respostas de pesquisadores e clínicos para tratar o problema. Se estas respostas centram-se de modo mais pragmático e técnico no restabelecimento da condição para o trabalho ou se assumem sua dimensão política, interpelando as condições degradantes e desgastantes do trabalho, a pergunta que aqui sustentamos é a mesma: que lugar para o sujeito do inconsciente? No sentido em que Lacan (1964/1988) o toma, trata-se do ponto em que, entre a causa e o que ela afeta, o inconsciente se situa onde algo tropeça. Deste modo, a questão não está na natureza da causa suposta ao efeito, na medida em que, para 
que o sujeito do inconsciente possa advir, a condição é que o saber sobre a causa comporte um limite, desde o qual se ponha em suspensão. É também neste sentido que Lacan acrescenta que, quanto à ideia de que o inconsciente determina a neurose, "Freud fez de bom grado o gesto pilático de lavar as mãos" (p.21). Isto é, podem vir a encontrar outros determinantes, não é isso que importa; o que importa na hipótese do inconsciente é ela se distinguir por nos mostrar essa hiância na qual advém o sujeito.

Foi através da hipótese do inconsciente, explorando-a em ato no contexto clínico, que a obra de Freud se fez e seguiu seus caminhos. A constatação de um mal-estar que está na base do laço social, por exemplo, é ponto de chegada desta obra que testemunha a exploração do campo do inconsciente. Ao chegar aí, por sua vez, Freud estabelece-o, desde então, como o que dá fundamento, como o que formaliza o ponto de partida da prática analítica. Ponto de partida que define, de saída, um limite articulado à esfera de um incurável, de algo estruturalmente sintomático. Não se trata de igualar os saberes e práticas no plano ético ou político, mas de condicionar a presença do sujeito do inconsciente a este limite sempre passível de se ver suprimido por um emprego do saber que não contemple uma falha estrutural ao tomar em consideração os fenômenos concernentes aos seres falantes, não importando aí a natureza do saber. Se evidentemente diferenciam-se em termos éticos e políticos as propostas hegemônicas e contra-hegemônicas, atentaremos, na sequência da discussão, para o risco de, em nome de um mais-desaber, estas últimas virem a ratificar uma ordem de coisas que se encontra bem assentada no que ela pretenderia contestar.

\section{O paradigma da depressão e a busca do nexo causal}

O aumento de casos de depressão relacionados ao trabalho é um fato que instiga equipes médicas, sindicalistas e administradores a uma tomada de posição com relação ao assunto. Seja na busca por encontrar as causas externas ou internas que fazem adoecer a fim de propor uma intervenção que restabeleça o trabalhador, seja num movimento contestatório das condições que adoecem tanto o corpo quanto a mente do conjunto dos trabalhadores, as duas abordagens, como propomos, não dão lugar ao sujeito do inconsciente. Ainda que estejam em jogo duas abordagens (Medicina do Trabalho/Saúde Ocupacional e Saúde do Trabalhador) sob muitos aspectos distintas, no que diz respeito à dimensão prática da questão, ambas se orientam no sentido de diagnosticar a doença que acomete o trabalhador. Afastam o trabalhador das suas funções, ele é medicado e determina-se um período para tratamento e reabilitação para o trabalho. Pode-se pensar que esse procedimento cabe bem para certos acometimentos, como 
uma lesão óssea, por exemplo. Mas o que pensar sobre esse mesmo procedimento num caso de depressão? Como se dá o diagnóstico dessa depressão e como se propõe um tratamento? Ainda, o que se pode ler dessa depressão para além de seu diagnóstico e tratamento?

A psiquiatria atual considera a depressão como uma doença do cérebro, que demonstra uma disfunção em seu funcionamento. Para tratá-la enfatiza, portanto, o déficit funcional, de base orgânica. Faz o diagnóstico a partir da observação e da descrição dos sinais que indicam a presença da doença. Tem a terapêutica farmacológica como principal indicação para o tratamento, administrando os chamados antidepressivos, que agiriam na regulação dos neurotransmissores. Afetos e outros estados da subjetividade tradicionalmente ligados à melancolia e ao luto passaram a estar sob a designação de depressão, entendida a mesma como uma "disfunção neuroquímica que deve ser corrigida com psicofármacos" (Teixeira, 2005, p.52-53) e considerada ainda subnotificada. Justificam-se, assim, os sistemas classificatórios correntes em psiquiatria, que facilitam o diagnóstico da depressão e buscam consenso entre os profissionais.

Esta entidade cujo imaginário circula dos manuais psiquiátricos para a vida cotidiana encontra sua representação também no mundo do trabalho. Se, em termos gerais, a depressão contrasta com um ideal de felicidade e de saúde/bem-estar a ser alcançado, este inclui a dimensão do ser produtivo. O que aparece como depressão na relação ao trabalho indica justamente que o indivíduo não é capaz de produzir e atender às exigências dessa produtividade, configurando um entrave para o mundo laboral por um lado e, por outro, para a sua própria realização pessoal. Esta incapacidade, subsumida pelo termo depressão, gera dificuldades para a gestão do quadro de pessoal nas instituições. Além de ser um problema para a produção, o é também para a economia, para a previdência e para a saúde pública. Neste sentido, e paradoxalmente, o sistema do capital terá que buscar a reabilitação desses acometidos para que possam voltar a ser produtivos, ao passo que o próprio sistema produziu esses depressivos. Produziu-os segundo a perspectiva crítica em que as afecções que a depressão vem a designar têm relação com as condições postas pelo próprio sistema produtivo; mas produziu-os também no sentido em que o sistema colocou-se como agente na expansão do diagnóstico de depressão em seu recobrimento das mais variadas formas de expressão de sofrimento, e aumento do mal-estar ( no caso, em sua manifestação no contexto do trabalho).

Seja pela via em que se diagnostica e reabilita o trabalhador, seja pela via em que se analisam as condições e a organização do trabalho e sua importância como causa da doença, os sintomas na depressão, objetivados, não reportam a um enigma que direcione ao sujeito. A depressão se torna, antes, um paradigma para o campo da saúde na 
interface com o trabalho. E mesmo a proposta contra-hegemônica, que pretenderia abordar a Saúde do Trabalhador além da perspectiva organicista, acaba por reiterar a hipótese neurobiológica subjacente ao diagnóstico da depressão se não inclui o mesmo no âmbito de sua crítica. A novidade nesse campo é justamente o estabelecimento de uma especialidade denominada Psiquiatria Ocupacional, que se utiliza de todo o aparato convencional (diagnóstico baseado no DSM ou CID10, psicofármaco associado à psicoterapia como instrumento terapêutico), com vistas a contribuir para o aperfeiçoamento da classificação diagnóstica das doenças relacionadas ao trabalho.

Neste sentido, denomina-se Nexo Técnico Epidemiológico a metodologia que objetiva identificar a relação entre a doença e a prática de atividades profissionais específicas. A finalidade de estabelecer um nexo causal entre a doença e o trabalho, ao não problematizar o modelo diagnóstico, acaba por naturalizar as entidades que lhe são próprias, em contradição com a suposição de que a Saúde do Trabalhador superaria o ponto de vista estrito das ciências naturais e ampliaria o foco da análise para além do individual biológico. Ao ganho suposto, para o trabalhador, em termos preventivos, previdenciários, de peritagem, cabe a pergunta se não se estaria, em contrapartida, reforçando aquilo que se supõe contestar. Se, diferente da Medicina do Trabalho, a Saúde do Trabalhador inclui em sua práxis a crítica ao modo de produção capitalista, ao ratificar o estatuto epidêmico da depressão nos termos da psiquiatria biológica, por melhor que sejam suas intenções, ela não estará reiterando uma ordem de coisas agenciada segundo a lógica do capital?

Para Selligmann-Silva (2007), por exemplo, a forma de diagnosticar a depressão afeita ao contexto de trabalho pode ser um ponto de partida para que os sistemas de saúde e os serviços médicos das empresas possam localizar nos processos de trabalho os fatores que promovem distúrbios psíquicos e assim fundamentar ações preventivas. A autora relata o avanço que houve no Brasil quanto ao registro das doenças psíquicas relacionadas ao trabalho a partir da publicação da Lista de Transtornos Mentais e do Comportamento Relacionados com o Trabalho em uma Portaria do Ministério da Saúde (Portaria No. 1339/GM, de 18 de novembro de 1999), bem como do Manual de Procedimentos para os Serviços de Saúde (Ministério da Saúde/OPS). Ao se utilizar dessas diretrizes, consolida-se um registro das doenças que identifica com maior clareza a relação dos adoecimentos psíquicos com o trabalho, o que contribui para os estudos epidemiológicos da área, bem como para ações preventivas mais assertivas.

Para além do registro diagnóstico, outros pontos são importantes para a Saúde do Trabalhador, relativos à conduta ante o caso e o acompanhamento do caso. Para essa abordagem em saúde, torna-se imprescindível proporcionar cuidados ao paciente com vistas a aliviar 
sua sintomatologia, avaliar com o paciente as possibilidades que ele tenha de modificar sua interação no local de trabalho, de modo a ficar mais favorável a ele, e orientá-lo sobre os riscos que corre ao ser exposto a um ambiente insalubre, diminuindo sua exposição aos mesmos. Investir, ainda, nos coletivos de trabalho para garantir a segurança e a proteção à saúde e, se for o caso, orientar a família sobre os distúrbios psíquicos relacionados ao trabalho e sobre seus efeitos na família. Certamente, trata-se de uma forma de compreender e tratar a doença que pretende extrapolar o corpo biológico, mas que, por isso mesmo, interrogamos se não comporta uma contradição ao naturalizar uma entidade diagnóstica como a da depressão na versão encontrada nos manuais diagnósticos.

Indicamos, acima, que o recurso à categoria da depressão que privilegia o estabelecimento de um nexo causal da doença com o trabalho, e não comporta a crítica da própria entidade diagnóstica, responde a razões de ordem epidemiológica, assistencial, previdenciária, mas também insere-se no contexto da crescente judicialização das relações de trabalho. Parte considerável das demandas colocadas para a Psiquiatria Ocupacional é relativa à emissão de pareceres sobre o prognóstico laborativo do pacientetrabalhador, mediante declaração ou atestado, e à elaboração de laudos técnicos, civis, criminais ou trabalhistas; ou seja, um serviço de peritagem a ser utilizado na esfera forense. Constata-se aí a incidência local de uma questão relevante na atualidade, referente à sobreposição no campo da saúde entre o domínio da perícia e o da clínica, com o primeiro produzindo sobre o segundo uma inflexão. No contexto de nossa discussão, pretendemos localizar aí mais um fator limitante à tomada do sujeito na via do inconsciente, com a desconsideração à dimensão de verdade à qual nela o sintoma se encontra associado. Seria, portanto, um dos aspectos da inflexão consequente à regência da técnica que a primazia da perícia sobre a clínica produziria.

\section{Considerações críticas desde uma perspectiva ética na clínica}

Não é a expertise técnica o que constitui o horizonte do que Lacan propõe sob a égide de um retorno a Freud. Ele enfatiza as implicações, antes de cunho ético, de uma teoria do inconsciente que considera aquilo que é impossível de se realizar no campo sexual. Acerca disso, retoma a leitura de Karl Marx e seu conceito de maisvalia para apreender na clínica a noção de sintoma articulável ao campo aberto por Freud. Para Lacan (1968-1969/2008), é Marx o inventor do conceito de sintoma, constatação que faz com que se empenhe em situar, no discurso analítico, uma função correlata à mais-valia. 
O que importa a Lacan na decifração de tal realidade econômica por Marx é que, ao ser o sujeito do valor de troca representado perante o valor de uso, nessa brecha "se produz e cai a chamada mais-valia" (Lacan, 1968-69/2008, p.21). É aí, no que ele entende haver de inaugural em Marx, que incide a homologia através da qual a perda em jogo passa a ser tomada nos termos do mais-de-gozar. Se, por um lado, Lacan se apoia na mais-valia para situar o mais-de-gozar "Trata-se do mesmo tecido" (p.44), por outro lado, o mais-de-gozar viria designar a função mais essencial do que, na investigação de Marx, por ter como objeto o capitalismo, figura nos termos de uma mais-valia. Neste sentido, segundo Lacan, esclarece-se que "o que Marx denuncia na mais-valia é a espoliação do gozo" (Lacan, 196970/1992, p.76). Por um passo retroativo em relação à homologia de que parte Lacan, a mais-valia é tomada, então, como o que equivale ao mais-de-gozar em Marx. "O Mehrwert é o Marxlust, o mais-degozar de Marx" (Lacan, 1970/2003, p.434).

Se a função do mais-de-gozar delimita o que é desapropriado do sujeito no sentido em que Freud já especificara o mal-estar na cultura, os sintomas estarão ligados aos discursos, a modos de laço social. Segundo Soler (2009), Lacan foi preciso ao tratar os sintomas que aparecem na clínica como sintomas ligados ao discurso, em designar que a estrutura do sujeito trabalha na história. Assim, entende que a relativa evolução dos sintomas na história da humanidade está diretamente relacionada ao estado do discurso, ou seja, deve-se considerar que o sujeito está impregnado pela ideologia que o discurso do capital institui. Deve-se considerar que o sintoma proposto por Freud é parte integrante do que foi inventado pelo discurso do capital: o sujeito livre para vender sua força de trabalho no mercado, mas que, nessa relação, desapropria-se de algo que lhe é muito íntimo e fundamental, o mais valor gerado pelo seu trabalho.

Se na esteira de Marx a Freud, o sintoma dá a verdade do sistema, o que podemos dizer da depressão?

Analisar o aumento significativo das depressões como sintoma do mal-estar social no século XXI significa dizer que o sofrimento dos depressivos funciona como sinal de alarme contra aquilo que faz água na grande nau da sociedade maníaca em que vivemos. Que muitas vezes as simples manifestações de tristeza sejam entendidas (e medicadas) como depressões graves só faz confirmar essa ideia. A tristeza, os desânimos, as simples manifestações da dor de viver parecem intoleráveis em uma sociedade que aposta na eufonia como valor agregado a todos os pequenos bens em oferta no mercado (Khel, 2009, p.31).

À compreensão do sintoma dando a verdade do sistema, passo ético inscrito no mal-estar freudiano, contrapõe-se a noção de que seu 
agrupamento constitui uma síndrome, um transtorno, um distúrbio, que precisa ser tratado, banido, pela via medicamentosa. A medicalização do sofrimento tem valor em uma sociedade que pouco tolera a incapacidade, a lentidão e a inadaptação dos sujeitos a um ideal de produtividade. Neste sentido, não só o sintoma, mas também a lógica do diagnóstico e do tratamento dão a verdade do sistema, o que os operadores do campo da Saúde do Trabalhador não detectam se dela se valem para denunciar e responder aos efeitos do modo de produção no capitalismo. Tal lógica se inscreve como um desses efeitos.

Tomando por divisa de sua ética na clínica o impossível a que reporta - mal-estar, para a psicanálise "o sintoma é o modo particular de inscrição do sujeito no discurso, ou seja, no laço social" (Vanier, 2002, p.216), Naquilo em que a clínica psicanalítica se diferencia, não toma o caso que chega a ela, por exemplo os de depressão, como igual a todos, mas o escuta em sua singularidade. Isso não significa que se esteja isento do discurso ideológico do capital. A clínica não é o lugar da neutralidade discursiva em que o espírito transcende. 0 tratamento do sintoma não significa necessariamente um tratamento que se encontra para além do sistema do capital. A emergência do sujeito do inconsciente não deve ser tomada como a emergência de um sujeito fora da determinação discursiva. Mas se, por seu lado, o campo da Saúde do Trabalhador, que se pretende voltado às demandas do trabalhador, não considera o sujeito do inconsciente, podemos perguntar se não está fadado a uma prática alienante, apesar de visar a denúncia da verdade do sistema. Há implicações em se conceber uma clínica que reabilita ou que conscientiza ou que responsabiliza:

Para Freud, a tristeza de um sujeito não é causada por um problema orgânico, e sim pela verdade que o habita, razão pela qual é, com frequência, lúcida. A tristeza é legítima quando há um luto. Quando se torna sintoma, mantém-se presente enquanto o desejo nela presente permanece amordaçado. Esse sintoma necessariamente íntimo está conectado, a um só tempo, ao mal-estar da sociedade e às suas prescrições de saber e poder ilimitados. Do mesmo modo, reduzir o humano a uma cadeia de neurônios e neurotransmissores é não apenas levá-lo à servidão, como também condená-lo a uma depressão definitiva (Aflalo, 2012, p.26).

O automatismo dos afastamentos suprime qualquer consideração sobre a responsabilidade subjetiva. A ideia de afastar o sujeito de suas atividades parte da suposição de que seus problemas associam-se à atividade laboral, a qual o impediria de realizar-se como sujeito. A verdade que o habita somente poderia ser manifesta fora do lugar do 
trabalho. Mas não se pode, neste caso, considerar o lugar da atividade como determinante pontual do qual se pode escapar pelo simples distanciamento físico. Esta atitude implicaria aceitar uma cisão definitiva e departamentalizada do sujeito ontológico, separando-o em "sujeito para si" e "sujeito para o trabalho", cada um com certa autonomia sobre o outro. O "sujeito para o trabalho" estaria irremediavelmente submetido ao poder avassalador do capital e somente poderia aspirar sua emancipação no momento clínico em que pudesse ser "sujeito para si".

Se a clínica é lugar da não vigilância direta, não é jamais lugar da neutralidade, da isenção e da ausência da incidência discursiva. Como o espaço da clínica não torna o sujeito imune aos determinantes de sua vida, é apenas no sentido da não vigilância opressora, que impede a livre manifestação, que se pode justificar o afastamento clínico. Em relação às práticas de intervenção, ao se colocar no lugar de fazer pelo trabalhador (denunciar o sistema, afastá-lo do trabalho, reabilitá-lo, promover o desenvolvimento de estratégias defensivas para subjetivamente dar conta do mal do trabalho), pode-se, ao contrário, impedir que o sujeito, em cena, mas desconsiderado, busque sua própria saída, que sempre será sintomática, o que não significa individual. Tal como a denúncia da lógica do sistema pode vir a apenas fortalecê-lo, já que a denúncia pelo acometido pode servir ao aprimoramento desta lógica, pode-se lançar a pergunta sobre os efeitos políticos das saídas que passem pelo sintoma de cada um.

\section{Referências}

Aflalo, A. (2012). O assassinato frustrado da psicanálise. Rio de Janeiro: Contra Capa.

Brasil. (1988) Constituição. Constituição da República Federativa do Brasil. Brasília, DF: Senado Federal: Centro Gráfico, 1988.

Brasil. (1999) Portaria no. 1339, Gabinete do Ministro, de 18 de novembro de 1999. Lista de Transtornos Mentais e do Comportamento Relacionados com o Trabalho. Diário Oficial, Brasília, DF.

Brasil (2001) Ministério da Saúde. Organização Pan-Americana da Saúde no Brasil. Doenças relacionadas ao trabalho: manual de procedimentos para os serviços de saúde. (Org.) Elizabeth Costa Dias; (colaboradores) Idelberto Muniz Almeida et al. Brasília: Ministério da Saúde.

Brasil. (2005). Ministério da Saúde. Secretaria de Atenção à Saúde. Departamento de Ações Programáticas Estratégicas. Legislação em saúde: caderno de legislação em saúde do trabalhador. (2.ed. rev. e ampl.). Brasília: Ministério da Saúde. 
Cruz, R. M. (2010). Nexo técnico e vigilância à saúde do trabalhador: uma agenda científica para o Ntep. In: Machado, J, Sorato, L., \& Codo, W. (Orgs.). Saúde e trabalho no Brasil: uma revolução silenciosa: o Ntep e a Previdência Social (pp.256-272). Petrópolis, RJ: Vozes.

Dejours, C., Abdoucheli, E. (1994). Itinerário teórico em psicopatologia do trabalho. In: Dejours, C., Abdoucheli, E., \& Jayet, C. Psicodinâmica do trabalho: contribuições da escola dejouriana à análise da relação prazer, sofrimento e trabalho. São Paulo: Atlas.

Dejours, C., Bègue, F. (2010). Suicídio e trabalho: o que fazer? Sobradinho, DF: Paralelo 15.

Freud, S. (1998a). A sexualidade na etiologia das neuroses. In: Obras psicológicas completas de Sigmund Freud: edição standard brasileira (vol. 3, v. 3, pp. 249-270). Rio de Janeiro: Imago. (Obra original de 1898).

Freud, S. (1998b). Três ensaios sobre a teoria da sexualidade. In: Obras psicológicas completas de Sigmund Freud: edição standard brasileira (vol. 7, v. 7, pp. 119-231). Rio de Janeiro: Imago. (Obra original de 1905).

Freud, S. (1998c). Moral sexual civilizada. In: Obras psicológicas completas de Sigmund Freud: edição standard brasileira (vol. 9, v. 9, pp. 167-186). Rio de Janeiro: Imago. (Obra original de 1908).

Freud, S. (1998d). Psicologia das massas e análise do eu. In: Obras psicológicas completas de Sigmund Freud: edição standard brasileira (vol. 18, v. 18, pp. 79-154). Rio de Janeiro: Imago. (Obra original de 1921).

Freud, S. (1998e). O futuro de uma ilusão. In: Obras psicológicas completas de Sigmund Freud: edição standard brasileira (vol. 21 , v. 21 , pp. 13-63). Rio de Janeiro: Imago. (Obra original de 1927).

Freud, S. (1998f). O mal-estar na civilização. In: Obras psicológicas completas de Sigmund Freud: edição standard brasileira (vol. 21 , v. 21 , pp. 67-148). Rio de Janeiro: Imago. (Obra original de 1930).

Freud, S. (1998g). Por que a guerra? In: Obras psicológicas completas de Sigmund Freud: edição standard brasileira (vol. 22 , v. 22 , pp. 191-208). Rio de Janeiro: Imago. (Obra original de 1933).

Khel, M. R. (2009). O tempo e o cão: a atualidade das depressões. São Paulo: Boitempo.

Lacan, J. (1988). O seminário, livro 11: os quatro conceitos fundamentais. Rio de Janeiro: Jorge Zahar Ed. (Seminário proferido em 1964). 
Lacan, J. (1992). O seminário, livro 17: o avesso da psicanálise. Rio de Janeiro: Jorge Zahar. (Seminário proferido em 1969-1970).

Lacan, J. (2003). Radiofonia. In: Lacan, J. Outros Escritos (pp. 400447). Rio de Janeiro: Jorge Zahar Ed. (Obra original de 1970).

Lacan, J. (2008). O seminário, livro 16: de um outro ao outro. Rio de Janeiro: Jorge Zahar. (Seminário proferido em 1968-1969).

Lacaz, F. A. de C. (1996). Saúde do trabalhador: um estudo sobre as formações discursivas da academia, dos serviços e do movimento sindical. Tese de Doutorado, Faculdade de Ciências Médicas da Universidade Estadual de Campinas, Campinas, São Paulo, SP, Brasil.

Lhuilier, D. (2011). Filiações teóricas das clínicas do trabalho. In: Bendassolli, P. F., \& Soboll, L. A. P. (Orgs.). Clínicas do trabalho: novas perspectivas para compreensão do trabalho na atualidade (pp. 22-58). São Paulo: Atlas.

Mendes, R., Dias, E. C. (1991). Da medicina do trabalho à saúde do trabalhador. Revista de Saúde Pública, 25, 341-349.

Mendes, R. \& Waissmann, W. (2007). Aspectos históricos da patologia do trabalho. In: Mendes, R. (Org.). Patologia do trabalho (vol. 1, v. 1. pp. 3-46). São Paulo: Atheneu.

Netto, N. B. (2013). Suicídio e Trabalho: breves considerações acerca da relação entre sofrimento e alienação. In: Navarro, V. L., Lourenço, E. A. S. (Orgs). O avesso do trabalho III: saúde do trabalhador e questões contemporâneas. (pp. 125-142) São Paulo: Outras Expressões.

Ramazzini, B. (2000). As doenças dos trabalhadores (1700). (Tradução de Raimundo Estrêla). (3. ed.) São Paulo: Fundacentro.

Rocha, L. E. (2010). Contribuições da medicina do trabalho para a psiquiatria ocupacional. In: Camargo, D. A., Caetano, D., \& Guimarães, L. A. M. (Orgs.). Psiquiatria ocupacional: aspectos conceituais, diagnósticos e periciais dos transtornos mentais e do comportamento relacionados ao trabalho (pp. 10-14). São Paulo: Atheneu.

Selligmann-Silva, E. (2007). Psicopatologia e saúde mental no trabalho. In: Mendes, R. (Org.). Patologia do trabalho (vol. 2, v. 2. pp. 1141-1182). São Paulo: Atheneu.

Selligmann-Silva, E. (2011). Trabalho e desgaste mental: o direito de ser dono de si mesmo. São Paulo: Cortez.

Soler, C. (2009). La querella de los diagnosticos. (Curso 2003-2004). Buenos Aires: Letra Viva.

Souza, P. C. Z., Athayde, M. (2006). A contribuição da abordagem clínica de Louis Le Guillant para o desenvolvimento da Psicologia do Trabalho. Estudos e Pesquisas em Psicologia, 6(1), 6-19. 
Teixeira, M. A. R. (2005). Melancolia e depressão: um resgate histórico e conceitual na psicanálise e na psiquiatria. Revista de Psicologia da UNESP, 4(1), 41-56.

Vanier, A. (2002). O sintoma social. Revista Ágora, 5(2), 205-217.

Waissmann, W., Castro, J. A. P. (1996). A evolução das abordagens em saúde e trabalho no capitalismo industrial. In: Teixeira, P. \&, Valle, S. (Orgs.). Biossegurança: uma abordagem multidisciplinar (pp. 15-25). Rio de Janeiro: Fiocruz.

\section{Endereço para correspondência \\ Elaine Cristina Schmitt Ragnini}

Universidade Federal do Paraná - UFPR

Praça Santos Andrade, 50, sala 206, 2ㅇaㅁ andar, Ala Alfredo Buffren, CEP 80060.240, Curitiba - PR, Brasil

Endereço eletrônico: elaineschmitt@hotmail.com

\section{Vinicius Anciães Darriba}

Universidade do Estado do Rio de Janeiro - UERJ

Rua São Francisco Xavier, 524, 10 andar, Maracanã, CEP 20550-011, Rio de Janeiro - RJ, Brasil

Endereço eletrônico: vdarriba@centroin.com.br

Recebido em: 08/20/2015

Aceito em: 23/11/2016

\section{Notas}

* Doutora em Educação pela Universidade Federal do Paraná (UFPR); Professora Adjunta Associada do Departamento de Psicologia da Universidade Federal do Paraná (UFPR).

** Doutor em Teoria Psicanalítica pela Universidade Federal do Rio de Janeiro (UFRJ); Professor Adjunto na Universidade do Estado do Rio de Janeiro (UERJ) Programa de Pós-Graduação em Psicanálise. 